Research Article

Open Access

\title{
Effect of Momoridica chorantia (Bitter Melon) Fruit extract on Homocysteine Levels and Lipid Profile in experimentally induced Hyperlipidemia in Rabbits
}

\author{
Jyoti Sethi $^{1 *}$ and Kiran Dahiya ${ }^{2}$ \\ ${ }^{\prime}$ Department of Physiology, Kalpana Chawla Government Medical College, Karnal, India \\ ${ }^{2}$ Department of Biochemistry, Pandit Bhagwat Dayal Sharma Post Graduate Institute of Medical Sciences, Rohtak, India
}

\section{Article Info \\ *Corresponding author: \\ Jyoti Sethi \\ Department of Physiology \\ Kalpana Chawla Government Medical College \\ Karnal-132001, Haryana \\ India \\ E-mail: dr_jyotisethi@rediffmail.com}

\section{Received: March 21, 2019 \\ Accepted: April 5, 2019 \\ Published: April 18, 2019}

\begin{abstract}
Citation: Sethi J, Dahiya K. Effect of Momoridica chorantia (Bitter Melon) Fruit extract on Homocysteine Levels and Lipid Profile in experimentally induced Hyperlipidemia in Rabbits. Madridge J Case Rep Stud. 2019; 3(2): 136-139.

doi: $10.18689 /$ mjcrs- 1000135
\end{abstract}

Copyright: (c) 2019 The Author(s). This work is licensed under a Creative Commons Attribution 4.0 International License, which permits unrestricted use, distribution, and reproduction in any medium, provided the original work is properly cited.

Published by Madridge Publishers

\begin{abstract}
Background: The major clinical sequelae of hyperlipidaemia are atherosclerosis, which is the leading cause of death worldwide. It has been estimated that up to one-third of the patients of cardiovascular disease with obesity use some form of complementary and alternative medicine.
\end{abstract}

Objective: The present study was planned to evaluate the effect of Momordica charantia on plasma homocysteine levels and lipid profile in experimental animals.

Material and methods: Albino rabbits $(1.5-2.5 \mathrm{~kg})$ of either sex were divided into three groups with six animals in each group. Group I received the standard chow diet; group II rabbits received HFD; and group III rabbits received HFD supplemented with aqueous MC fruit extract (100 mg/kg). After 14 weeks of the experimental period, animals were fasted overnight and blood was taken for estimation of total cholesterol (TC), triglyceride (TG), high density cholesterol (HDL-C) and homocysteine.

Results: MC significantly lowered the TC and TG levels in Group III rabbits as compared to Group II. In rabbits fed on HFD, Homocysteine and TC were significantly increased.

Conclusion: This study suggests that MC can prove to be a significant cardioprotective substance and an important adjuvant in the treatment of hyperhomocysteinemia and dyslipidemia.

Keywords: Momordica charantia; High-fat diet; Cardioprotective; Homocysteine; Atherogenic indices.

Abbreviations: MC: Momordica chorantia; HFD: High Fat Diet; TC: Total Cholesterol; TG: Triglycerides; HDL-C: High Density Lipoprotein; LDL: Low Density Lipoprotein; Hcy: Homocysteine; CHD: Coronary Heart Disorder.

\section{Background}

Atherosclerosis has been found to be the most frequent cause of myocardial infection, stroke and peripheral vascular disease. Hypercholesterolemia and hyperlipidemia were previously recognized as causative agents for it, extending the area to lipoproteins especially low-density lipoprotein (LDL) as the most potential causative agents [1]. Recent evidences indicate that $L D L$ in its native form may not be so but when oxidised by the oxidants, produced in vivo, becomes atherogenic [2]. Hypolipidemic drugs have their limitation due to their side effects, non-compliance due to prolonged use and rebound effect after withdrawal. Therefore, the judicious use of certain medicinal plants and drugs has been found to be effective in numerous clinical and experimental trials [3]. 
Momordica charantia (MC) is a member of cucurbitaceae family (also known as bitter gourd or karela), and is traditionally used as a food in South Asia. The roots, leaves, seeds and fruits of this plant have been used in traditional medicine for treating various diseases [4]. There are studies showing the hypoglycaemic [5], antipyretic, antibacterial [6], antihelminthic, antimalarial [7], antiulcerogenic [8] and immunomodulatory [9] properties of MC. The medicinal value of the Momordica charantia fruit extract has been attributed to its high antioxidant properties, due in part to the presence of phenols, flavonoids, isoflavones, terpenes, anthroquinones and glucosinolates, all of which confer a bitter taste. The fruit is also rich in minerals, including potassium, calcium, magnesium, phosphorous and iron, and is a good source of dietary fibre [10].

Homocysteine (Hcy) is a sulphur containing non-essential amino acid formed from demethylation of methionine. Homocysteine has been recognized as a risk factor as early as 1990s, for the development of atherosclerotic vascular disease and hypercoagulability states [11]. In our previous study, Momordica charantia was reported to reduce the levels of cholesterol and triglycerides (TG) and to increase the levels of high density lipoprotein cholesterol (HDL-C) in serum, but its effect on homocysteine has not been reported in the literature yet. Therefore, the present study was planned to study the effects of the aqueous extract of Momordica charantia on serum homocysteine levels and atherogenic index in experimentally induced hyperlipidemia in rabbits.

\section{Materials and Methods}

\section{Animals}

Albino rabbits of either sex weighing $1.5-2.5 \mathrm{Kg}$ were used as subjects for this study. Animals were procured from disease free animal house of CCS Haryana Agriculture University, Hisar (Haryana, India). They had free access to food and water and were maintained under 12:12 hour light and dark cycles. Institutional Animal Ethical Committee (IAEC) approved the experimental protocol (No. Phy/09/413 dated 13.5.09) and care of animals was taken as per guidelines of CPCSEA, Department of Animal Welfare, Government of India.

\section{Experimental design}

Rabbits were divided into three groups of six each, depending on the diet received.

Group I ( $(\mathbf{=}=6)$ : Rabbits received standard chow diet throughout the experiment for 14 weeks (Control group).

Group II ( $\mathbf{n = 6}$ ): Rabbits received high fat diet [12] (HFD) daily throughout the experiment for 14 weeks (HFD group).

Group III ( $n=6)$ : Rabbits received aqueous MC fruit extract (100 mg/Kg, p.o.) daily along with HFD for 14 weeks (HFD with MC group).

The composition of two diets [12] was as follows:

Control diet: Wheat flour $22.5 \%$, roasted Bengal gram powder $60 \%$, skimmed milk powder $5 \%$, casein $4 \%$, refined oil $4 \%$, salt mixture with starch $4 \%$ and vitamins and choline mixture $0.5 \%$.
HFD: Wheat flour $20.5 \%$, roasted Bengal gram powder $52.6 \%$, skimmed milk powder $5 \%$, casein $4 \%$, refined oil $4 \%$, coconut oil $9 \%$, salt mixture with starch $4 \%$, vitamins and choline mixture $0.5 \%$ and cholesterol $0.4 \%$.

Aqueous extract from powdered fruit of Momordica charantia was prepared by standard procedure. Oral dose of the extract was selected after a pilot study using three doses i.e. 50, 75 and $100 \mathrm{mg} / \mathrm{Kg}$. All the drugs were administered orally (using an intragastric tube) as a single dose in the morning.

\section{Sample collection}

After 14 weeks, blood samples were collected from the marginal vein of the pinna of overnight fasted rabbits in EDTA (ethylene diamine tetra acetic acid) vacutainers. The plasma was separated immediately and subjected to estimation of lipid profile. Total cholesterol (TC), high density lipoprotein cholesterol (HDL-C) and triglycerides (TG) were estimated on autoanalyser (Konelab 30i, Trivitron) by enzymatic methods using kits by Randox [13]. Homocysteine was estimated by immunoassay using direct chemiluminometer [14] (Advia Centaur, Siemens). Atherogenic Index (Al), which is a measure of the atherogenic potential of an agent [15], and protection percentage were calculated using the following formulas and the results were tabulated.

Atherogenic index $=\frac{(\text { Total cholesterol }-\mathrm{HDL})}{\mathrm{HDL}}$

Protection $(\%)=$

$\frac{\text { Atherogenic index of control-Atherogenic index treated group }}{\text { Atherogenic index of control }} \times 100$

\section{Statistical analysis}

Results were expressed as mean \pm SEM of six rabbits in each group. Data was analyzed statistically using SPSS software version 14.0 in each group by applying students' $t$ - test (unpaired).

\section{Results}

The results reveal that feeding of atherogenic diet increased serum levels of total cholesterol, triglycerides, homocysteine and decreased serum HDL-C levels when compared to normal group over a period of 14 weeks. Administration of Momordica charantia fruit extract along with atherogenic diet (group III) led to statistically significant decrease in total cholesterol, triglycerides and homocysteine levels as compared to animals on atherogenic diet only (group II) (Table 1). At this time an increase of HDL-cholesterol level was also observed. Momordica charantia treated animals showed decrease in the atherogenic index and increased percentage of protection.

Table 1. Lipid profile, atherogenic index and homocysteine levels in rabbits in different experimental groups.

\begin{tabular}{|c|c|c|c|c|c|}
\hline Group & $\begin{array}{c}\mathrm{TC} \\
(\mathrm{mg} / \mathrm{dL})\end{array}$ & $\begin{array}{c}\mathrm{TG} \\
(\mathrm{mg} / \mathrm{dL})\end{array}$ & $\begin{array}{l}\text { HDL-C } \\
\text { (mg/dL) }\end{array}$ & $\begin{array}{c}\text { Atherogenic } \\
\text { index }\end{array}$ & $\begin{array}{c}\text { Homocysteine } \\
(\mu \mathrm{mol} / \mathrm{L})\end{array}$ \\
\hline $\begin{array}{l}\text { Group I } \\
\text { (Control) }\end{array}$ & $93.00 \pm 0.01$ & $67.33+0.74$ & $27.33 \pm 0.49$ & 2.40 & $17.08 \pm 8.75$ \\
\hline $\begin{array}{l}\text { Group II } \\
\text { (HFD) }\end{array}$ & $\begin{array}{c}130.16 \pm \\
0.70^{\star * * a}\end{array}$ & $\begin{array}{l}98.33+ \\
0.49 * * * a\end{array}$ & $21.33 \pm 0.96^{\star \star a}$ & $5.10^{\star \star \star a}$ & $22.68 \pm 9.25^{\star * a}$ \\
\hline $\begin{array}{l}\text { Group III } \\
\text { (HFD+MC) }\end{array}$ & $\begin{array}{l}121.33 \pm \\
1.20^{\star * * a, b}\end{array}$ & $\begin{array}{c}53.11+ \\
0.80^{\star * * a, b}\end{array}$ & $22.14 \pm 0.47^{\star b}$ & $4.48^{* \star \star a, b}$ & $\begin{array}{l}19.98 \pm \\
5.23^{* * a, b}\end{array}$ \\
\hline
\end{tabular}

level of significance: ${ }^{*}: p<0.05 ;{ }^{* *}: p<0.01 ;{ }^{* * *}: p<0.001$

a: significant difference from animals in control group.

b: significant difference from animals in HFD group. 


\section{Discussion}

Dyslipidemia is an important risk factor in the initiation and progression of atherosclerotic lesions [6] and has promoted widespread search for plant based compounds which effectively control the lipid profile in the blood and tissues with least or no toxic effect. High fat diet feeding in laboratory animals leads to an elevation of plasma lipids such as cholesterol, fatty acids, and TG [17]. In accordance with studies by Park et al. [18], in the present study also, high fat diet feeding in laboratory animals for 14 weeks resulted in obesity and hyperlipidemia as evidenced by the enhanced levels of TC, TG and decreased HDL-C level in group II animals. One of the reason for increase in coronary heart disorder $(\mathrm{CHD})$, being observed in the developing countries since past few decades is an increase in intake of fast foods, which are rich in saturated fats [19]. Atherogenic lipid profile (increased TC and TG and decreased HDL-C) is often associated with increased propensity for developing CHD [20].

Lowering of plasma lipid levels through diet or drug therapy is associated with a decrease in the risk of CHD [21]. In the present study, the levels of total serum cholesterol, triglyceride and homocysteine which were increased in group II, were lowered significantly with $M C$ fruit extract supplementation group III (HFD+MC). He et al. have reported the hypolipidemic and antioxidant potential of bitter gourd leaf extract in HFD fed mice [22].

Atherogenic indices are powerful indicators of the risk of heart disease, a higher value indicating a higher risk of developing cardiovascular disease [23]. In the present study, atherogenic index was significantly decreased in the Momordica charantia fruit extract group; probably by an increase in plasma HDL-cholesterol with a concomitant percentage decrease of atherogenic lipids. The percentage of protection against the hyperlipidemia in the plant extract treated group was $12.15 \%$, which further confirms the significant protective effect of the Momordica charantia fruit extract against hyperlipidemia. A $1 \%$ decrease in HDLcholesterol is associated with a $3-4 \%$ increase in the risk of heart disease. For male and female, concentration of HDLcholesterol below 1.0 and $1.2 \mathrm{mmol} / \mathrm{L}(39,46 \mathrm{mg} / \mathrm{dL})$ and especially below 0.8 and 1.0 and $1.2 \mathrm{mmol} / \mathrm{L}(31,39 \mathrm{mg} / \mathrm{dL}$ ) confer an increased risk of $\mathrm{CHD}$, whereas concentration exceeding 1.5 and $1.7 \mathrm{mmol} / \mathrm{L}(58,66 \mathrm{mg} / \mathrm{dL})$ diminishes the influence of other risk factors [24].

Rohajatien et al. [25] reported improvement of lipid profile in diabetic animals treated with bitter melon and attributed it to inhibition of cholesterol absorption by diosgenin (a steroidal sapogenin), dietary fibre, and phytosterol content of bitter melon fruit. In a randomized controlled trial conducted by Kumari et al. [26], type-2 diabetes mellitus patients were supplemented with Momordica charantia tablets along with oral antidiabetic agents. They reported favourable effect of Momordica charantia on fat metabolism and concluded that Momordica charantia could prevent cardiovascular risk in type 2 diabetes mellitus by improving dyslipidemia. The Momordica charantia fruit consists of glycosides, saponins, alkaloids, reducing sugars, resins, phenolic constituents, fixed oils and free acids. Effects are likely induced by more than one bioactive ingredients present in the Momordica charantia [27].

Evidence is emerging that the risk for cardiovascular disease from hyperhomocysteinemia may be additive to abnormalities in lipid metabolism. High homocysteine levels in the blood causes oxidation of low density lipoprotein which damages the arteries by creation of a plaque inside artery walls [28].

\section{Conclusion}

Synthetic hypocholesteromic drugs such as statins, fibrates, resins and nicotinic acid though efficiently reduce plasma TC levels, but LDL does not undergo any significant alteration. Moreover, synthetic hypolipidemic agents usually have one or more side effects and are unable to increase HDL levels [29]. It is well known that the oxidative modification of LDL plays a pivotal role in the progression of atherosclerosis and plaque formation [20] and fruit extract of Momordica charantia with its potential to reduce plasma cholesterol, TG and homocysteine levels can provide protection against hypercholesterolemia and also enhance the safety profile by elevating HDL levels. Thus, Momordica charantia may be utilized for providing dietary management in the prevention of atherosclerosis in hyperlipidemic patients.

\section{Declarations}

\section{Ethics approval and consent to participate}

All animal experimentation protocols were approved by Institutional Animal Ethical Committee (IAEC), and in agreement with the Ethical Principles for Animal Research established by CPCSEA, Department of Animal Welfare, Government of India.

\section{Consent for publication}

Not applicable

\section{Availability of data and materials}

The datasets generated and analyzed during the current study is available from the corresponding author on reasonable request.

\section{Competing interests}

The author declares no competing interests.

\section{Funding}

The research reported is funded by personal means.

\section{Authors' contributions}

Dr Jyoti Sethi contributed in planning, execution of methodology and compilation and analysis of data in writing of the paper.

Dr Kiran Dahiya contributed in planning, execution of the biochemical samples, analysis of data and writing of the biochemical aspect in the paper. 


\section{Acknowledgements}

We acknowledge the contribution of technical staff of Physiology and Biochemistry.

\section{References}

1. Holwes Jr DR, Elveback LR, Frye RL, Kottke BA, Ellefson RD. Association of risk factor variables and coronary artery disease documented with angiography. Circulation. 1981; 63(2): 293-299.

2. Keany JF Jr, Frie B. Antioxidant protection of low density lipoprotein and its role in prevention of atherosclerotic vascular disease. In: Frei B (ed). Natural antioxidants in health and disease. Orlando: Academic Press. 1994; 303-351.

3. Dwiedi S. Putative use of Indian cardiovascular friendly plants in preventive cardiology. Ann Nat Acad Med Sci (India). 1996; 32(3\&4): 159-175.

4. Sharma PC, Velne MB, Dennis TJ, Joshi A. Database on medicinal plants used in Ayurveda. Volume 4. New Delhi: Central Council for Research in Ayurveda and Siddha, Department of ISM \&H, Ministry of Health and Family Welfare, Government of India. 2005; 288-319.

5. Ahmed N, Hassan MR, Halder H, Brennoor KS. Effect of Momordica charantia extracts on fasting and post prandial serum glucose levels in NIDDM patients. Bangladesh Med Res Counc Bull. 1999; 25(1): 11-13.

6. Anwar Z, Ayub N, Khan AG. Antibacterial ability of extracts from arbuscular mycorrhizal roots of Allium sativum $L$ and Monordica charantia. Hamdard Med. 2000; 43(1): 29-33.

7. Amorim CZ, Marques $A D$, Cordeiro RS. Screening of antimalarial activity of plants of the cucurbitaceae family. Mem Inst Oswaldo Cruz. 1991; 86: 177-180.

8. Gurbuz I, Akyuz C, Yesilada E, Sener B. Antiulcerogenic effect of Momordica charantia L. fruits on various ulcer models in rats. J Ethnopharmacol. 2000; 71: 77-82.

9. Basaran AA, Ceritoglu I, Undeger U, Basaran N. Immunomodulatory activity of some Turkish medicinal plants. Phytother Res. 1997; 11(8): 609611.doi:10.1002/(SICI)1099-1573(199712)11:8<609::AID-PTR165>3.0.CO;2-0

10. Bakare RI, Magbagbeola OA, Akimwande Al, Okunowo O. W. Nutritional and chemical evaluation of Momordica charantia. J Med Plant Res. 2010; 4(21): 2189-2193.

11. Fonseca V, Guba SC, Fink LM. Hyperhomocysteinemia and the endocrine system: Implications for atherosclerosis and thrombosis. Endocr Rev. 1999; 20(5): 738-759. doi: 10.1210/edrv.20.5.0381

12. Muthu AK, Sethupathy S, Manavalan R, Karar PK. Antioxidant potential of methanolic extract of Dolichos biflorus Linn in high fat diet fed rabbits. Ind J Pharmacol. 2006; 38: 131-132.

13. Gordel T, Castelli WP, Hjortland MC. High density lipoprotein as a protective factor against coronary heart disease. The Framingham Study. Am J Med. 1977; 62: 707-714.

14. Refsum $H$, Ueland $P M$, Nygård $O$, Vollset SE. Homocysteine and cardiovascular disease. Annu Rev Med. 1998; 49: 31-62.
15. Yokozawa TE, Cho J, Sasaki S, Satoh A, Okamoto T, Sei Y. The Protective Role of Chinese Prescription Kangen-karyu Extract on Diet-Induced Hypercholesterolemia in Rats. Biol Pharm Bull. 2006; 29(4): 760-765.

16. Goldstein JL, Hazzard WR, Schrott HG, Bierman EL, Motulsky AG. Hyperlipidemia in coronary heart disease. J Clin Invest. 1973; 52(7): 153-157.

17. Feng $\amalg, \mathrm{Yu} C \mathrm{CH}$, Ying KJ, Hua J, Dai X. Hypolipidemic and antioxidant effects of total flavonoids of Perilla Frutescens leaves in hyperlipidemia rats induced by high-fat diet. Food Res Int. 2011; 44: 404-409. doi: 10.1016/j.foodres.2010.09.035

18. Park S, Park NY, Valacchi G, Lim Y. Calorie restriction with a high-fat diet effectively attenuated inflammatory response and oxidative stress-related markers in obese tissues of the high diet fed rats. Mediators Inflamm. 2012; 2012: 984643. doi: 10.1155/2012/984643

19. Kulkarni SK, Kaur G. Obesity: an insight into its neurochemical basis and treatment. Ind J Pharmacol. 1999; 31(6): 388-403.

20. Aviram M. Modified forms of low density lipoprotein and atherosclerosis. Atherosclerosis. 1993; 98: 19.

21. Shen GX. Lipid disorders in diabetes mellitus and current management. Curr Pharm Anal. 2007; 3: 17-24. doi: 10.2174/157341207779802386

22. He Q, Li Y, Li H, et al. Hypolipidemic and antioxidant potential of bitter gourd (Momordica charantia L.) leaf in mice fed on a high-fat diet. Pak J Pharm Sci. 2018; 31(5): 1837-1843.

23. Usoro CAO, Adikwuru CC, Usoro IN, Nsonwu AC. Lipid profile of postmenopausal women in calabar, Nigeria. Pak J Nutr. 2006; 5: 79-82. doi: 10.3923/pjn.2006.79.82

24. Ahirwar B, Singhai AK, Dixit VK. Effect of Terminalia chebula fruits on lipid profiles of rats. Journal of Natural Remedies. 2003; 3(1): 31-34. doi:10.18311/jnr/2003/359

25. Rohajatien U, Harijono, Estiasih T, Sriwahyuni E. Bitter Melon (Momordica Charantia L) Fruit Decreased Blood Glucose Level and Improved Lipid Profile of Streptozotocin Induced Hyperglycemia Rats. Curr Res Nutr Food Sci. 2018; 6(2): 359-370.

26. Kumari S, Dash I, Behera KK. Therapeutic Effect of Momordica charantia on Blood Glucose, Lipid Profile and Oxidative Stress in Type 2 Diabetes Mellitus Patients: A Randomised Controlled Trial. J Clin Diagn Res. 2018; 12(9): $B C 21-B C 25$.

27. Liu J, Chen J, Wang C, Qui M. New cucurbitane triterpenoids and steroidal glycoside from Momordica charantia. Molecules. 2009; 14: 4804-4813. doi: 10.3390/molecules 14124804

28. Kapoor P, Ansari MN, Bhandari U. Modulatory effect of curcumin on methionine -induced hyperlipidemia and hyperhomocysteinemia in albino rats. Indian J Exp Biol 2008; 46(7): 534-540.

29. Tenenbaum A, Fisman EZ. Fibrates are an essential part of modern anti dyslipidemic arsenal: spotlight on atherogenic dyslipidemia and residual risk reduction. Cardiovasc Diabetol. 2012; 11: 125. doi: 10.1186/14752840-11-125 